\title{
IDENTIDAD Y EMPODERAMIENTO DE MUJERES GAMBIANAS A TRAVÉS DE DISCURSOS FOTOGRÁFICOS
}

ILEANA LANDEROS CASILLAS ${ }^{1}$

\section{RESUMEN}

Con el objetivo de reconocer la construcción de la identidad y el empoderamiento de las mujeres de África Occidental, por primera vez en Lamin, Gambia, se realizó un estudio informal con mujeres que fotografían su entorno y hacen composiciones que reflejan su vida y cotidianidad. Estos retratos contradicen la imagen que tiene el mundo de África. Las fotos y sus discursos ponen al descubierto que la ayuda internacional debe insertarse a partir de su cosmovisión de vida y respetando la forma en que se apropian de los ecos de la poscolonialidad para construir en su diferencia. El discurso global se analiza desde la horizontalidad de Entre Voces, una metodología horizontal para el análisis de la comunicación entrecultural a través de la autoría de dos o más voces, que permite que el "otro", sea quien sea, se defina a sí mismo desde su propia mirada. También se tomaron en cuenta los estudios subalternos, la perspectiva de género, los discursos feministas y la educación artística.

Palabras claves: Mujeres, empoderamiento, identidad y fotografía.

\footnotetext{
1 Doctora en Artes Visuales y Educación por la Universidad de Granada. Profesora investigadora del Centro Universitario de Ciencias Sociales y Humanidades de la Universidad de Guadalajara, México. Av. Juárez No. 976, Centro. Código Postal 44100, Guadalajara, México. Correo electrónico: I_ileana@hotmail.com
} 


\section{IDENTITY AND EMPOWERMENT OF GAMBIAN WOMEN THROUGH PHOTOGRAPHIC SPEECHES}

\section{ABSTRACT}

With the objective to recognize the construction of identity and empowerment of Gambian women, it was conducted a study for the first time in Lamin, Gambia, in which women photograph their own environment and make compositions that reflect everyday life. These portraits contradict the image that the world have about Africa. The photos and their speeches expose that international support should be inserted from their cosmovision of life and respecting the way they appropriate the echoes of postcoloniality to build on its difference. The global discourse is analyzed from the horizontality of Entre Voces, an horizontal methodology for the analysis of intercultural communication through the authorship of two or more voices, that allows the "other", whoever they are, to define themselves from their own gaze. They were also considered subaltern studies, gender perspective, feminist discourses and artistic education.

Keywords: Women, empowerment, identity and photography.

\section{Introducción}

Este artículo es el resultado de una propuesta de intervención realizada en los años 2013 a 2014 en la comunidad de Lamin, en Gambia, con las madres de familia de algunos estudiantes de la escuela Canarias-Lamin Nursey School ${ }^{2}$. El objetivo fue sentar las bases de la Red de Mujeres Trabajadoras de Lamin, a través de un programa de educación artística informal donde la fotografía, como herramienta de investigación, permitiera a las mujeres visualizar y valorar sus tradiciones. Las reflexiones de sus imágenes, junto con los discursos verbales y las discusiones grupales sobre sus hallazgos, permitieron replantear proyectos y

\footnotetext{
2 Las madres de familia con las que se trabajó en este proyecto fueron las fundadoras de la escuela Canarias-Lamin Nursey School alrededor del año 2000.
} 
propuestas en común, nacidos desde las necesidades de la comunidad, con la finalidad de comercializar productos con algunas Organizaciones No Gubernamentales (ONGs) que deseen colaborar en esa comunidad.

Para hablar de las mujeres gambianas en el mundo contemporáneo es necesario comprender su actuar, entendiendo primero el contexto general al que pertenecen. Esto quiere decir que se deben tener en cuenta los efectos y transformaciones que el contacto con la civilización occidental causó en la civilización africana, la cual se vio profundamente afectada por el proceso histórico que marcó el paso de los sistemas tradicionales a los sistemas coloniales. Este cambio fue violento y radical respecto a los sistemas propios, dando como resultado un sistema híbrido. El sistema tradicional proporcionaba a la mujer una seguridad y estabilidad muy superior a la que se puede derivar de la propiedad privada (Algora, 2003).

Es evidente que la presencia europea transformó por completo la vida africana. Las estructuras y relaciones sociales, creencias, costumbres y el sistema económico. Se deshicieron los imperios y sometieron a los dirigentes autóctonos que, aunque se resistieron, acabaron claudicando ante la acción de los europeos. De esta forma se fracturó el equilibrio cultural y material existente, siendo sustituido por una relación de dependencia generada por la instalación del sistema capitalista. El capitalismo, integrado en una economía y comercio mundial, explotó los recursos de África y obligó a los pueblos a trabajar, no para sí mismos sino para el desarrollo europeo (Jabardo, 2005).

Bajo este panorama, la mujer africana en general y la gambiana en particular se vio en la necesidad de reinventarse y encontrar su lugar en esta amalgama de situaciones. Si bien el lugar, la jerarquía y las actividades de las mujeres se vieron afectadas, y por consecuencia la evolución de sus sistemas de producción, comercialización, interacción, etc., también se afectaron las costumbres sociales que regían el trabajo por sexo y grupos de edad.

Actualmente en las zonas rurales de Gambia se pueden apreciar con mayor claridad las características de la sociedad tradicional. Existen particularidades que 
tienen que ver con las actividades del campo y la producción de alimentos, labor que normalmente realizan las mujeres además de las actividades domésticas, la recolección de leña y el acarreo del agua (Algora, 2003). Sin embargo, día a día son más las mujeres que hacen un lado las creencias tradicionales y realizan trabajos que las sitúan en posiciones de empoderamiento, con el único objetivo de subsistir, alimentar a sus familias y tener un futuro mejor.

Lamin es un ejemplo actual de transición y su posición geográfica ha contribuido en el cambio de roles entre las mujeres. Se trata de una comunidad rural, pero que a pasos agigantados se incorpora a la urbana. Muchas mujeres han dejado de lado los trabajos tradicionales en el campo para unirse y ofertar productos, que suponen una mejoría a su economía, al turismo que a diario pasa por su comunidad rumbo a Lamin Lodge3; turismo que no solo obtiene de ellas sus productos, sino también sus imágenes, las mismas que serán distribuidas como parte de la cosmovisión del extranjero, sin que la opinión de ellas tenga relevancia.

Este trabajo pretende conocer, reconocer y utilizar el lenguaje creativo dominante de nuestra época, el lenguaje audiovisual, como una herramienta necesaria para cualquier persona que desee comprender la realidad en la que se encuentra inmerso. La fotografía para este estudio es una herramienta que permite adentrarse, no solo en la concepción estética y ética de una comunidad y llegar a conocer su posición frente a determinadas situaciones y temas, como los valores, las normas, las jerarquías, los roles de las distintas personas en la vida cotidiana y las prioridades, entre otros, sino que también permite identificar fortalezas, debilidades, miedos, deseos y problemáticas de las comunidades involucradas.

Cuando se comenzó a trabajar con las madres de familia de Lamin, se pensó en hacer una actividad artística, ya que el arte es algo que ellas reconocen y está presente dentro de su cultura. Esto debido a que en Gambia, al igual que en el resto del mundo, las personas han creado y utilizado el arte para representar

\footnotetext{
${ }_{3}^{3}$ Un popular embarcadero que oferta viajes por el Río Gambia para estar en contacto con la vida salvaje.
} 
sus sistemas de creencias religiosas e ideas sobre el poder político, para dejar constancia de su historia, describir los acontecimientos importantes en sus vidas y las vidas de sus comunidades, o para decoración del entorno en que viven, la ornamentación personal o el embellecimiento de los objetos cotidianos que utilizan.

La fotografía, en ese mismo sentido, es una herramienta que ha permitido narrar realidades, por lo que para este proyecto fue importante que las mujeres se concibieran activas y se reconocieran en su entorno a través de una imagen inmediata y participativa. De acuerdo con Wang y Burris (1997), las personas pueden identificar, representar y mejorar su comunidad a través de imágenes. Inspirados en la metodología Photovoice, se confiaron las cámaras a manos de las personas para permitirles actuar como documentadoras y catalizadoras potenciales del cambio en sus propias comunidades. Trabajar colectivamente con este grupo de mujeres fue, en principio, reconocerlas como parte importante de la sociedad y valorar el poder que ejercen dentro de su comunidad. Como señalan Deere y León (2002), el empoderamiento no es un proceso lineal, con un principio y un fin claramente definido y común para todos los individuos -en este caso las mujeres- sino que es un proceso que se experimenta de manera diferenciada y de alguna manera única por cada individuo, y se define y desarrolla en función de la historia personal y del contexto de cada quien.

En tal sentido, se plantea que el empoderamiento puede ocurrir por efectos de experiencias diversas, tales como procesos educativos, organizativos, laborales, etcétera. Por tal razón, como la misma Seera Manneh, "la dama de la sociedad"4 como cariñosamente le llaman, expresó en una de las primeras reuniones: "todas estamos en la misma rapa, si la rapa ${ }^{5}$ se rasga no solo cae una, caemos todas".

\footnotetext{
${ }^{4}$ Seere Manneh, es la primera esposa del Alcalde de Lamin. Tiene un lugar sobresaliente en esa comunidad por su linaje familiar, su edad y por las acciones experimentadas en bien del desarrollo de las mujeres.

${ }^{5}$ Rapa es la tela que utilizan las mujeres para sujetar a sus hijos en la espalda.
} 


\section{Gambia y la comunidad de Lamin}

Figura 1. Mapa de Gambia.

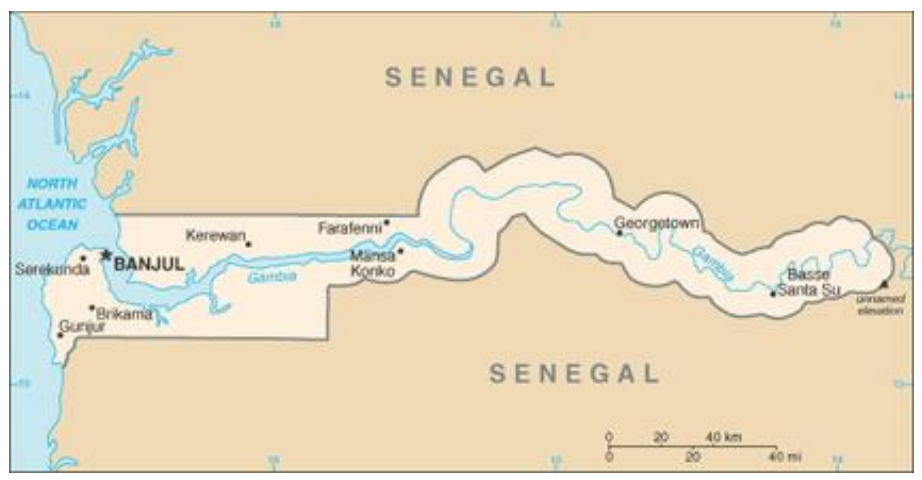

Fuente: Google maps (s.f.)

La región donde se desarrolla este estudio es en Gambia, una nación cuyos únicos límites son Senegal y el océano Atlántico. Habitan 1.7 millones de personas aproximadamente, y se caracteriza por un flujo constante de nacionalidades y culturas, es decir, por la interculturalidad de razas y tribus que conviven pacíficamente. Según datos del Gobierno Gambiano se destacan cuatro tribus principalmente: mandinkas, wolof, jolas y fulas. La lengua oficial es el inglés (Kane, 2007).

Las ciudades son prácticamente inexistentes, aunque hay ocho enclaves de más de 10 mil habitantes: Banjul, Bakau, Basse Santa Su, Brikama, Karafenni, Kaniffing, Serrekunda y Yudum. Como en muchos países africanos, en Gambia las estructuras sociales están basadas en la vida comunitaria que sigue siendo muy importante en los poblados, ya que después de la pertenencia a la familia, es el arraigo a la aldea el que da sentimiento de fortaleza y protección.

Gambia es un país mayoritariamente musulmán. Aproximadamente el 92\% de su población profesa esta religión, de manera quelos hombres musulmanes pueden tomar hasta cuatro esposas. Sin embargo, sus mujeres no se asemejan a las de países islámicos donde las mujeres apenas participan en la vida pública y solo salen de sus casas vestidas de negro (Moualhi, 1997; Lütz, 1991; Fanon, 
1972), como lo señala Olaya Fernández (2011) cuando explica la injerencia directa que tiene la interpretación del Corán dentro de esa sociedad. Por el contrario, las mujeres gambianas están por todas partes y suelen ir alegremente vestidas, con trajes de colores brillantes y estampados, con cortes ceñidos que realzan sus cuerpos. Enseñan sus brazos y lucen escotes sin ningún problema. Saben llamar la atención, se las ve decididas y enérgicas, se ocupan de la familia y, a menudo, también trabajan fuera de casa o tienen pequeños puestos en donde venden alguna mercancía.

Las mujeres normalmente viven con sus padres hasta que se casan, momento en el que pasan a formar parte de la familia del marido. Lo normal es que los miembros de una familia bajo el mismo techo sean numerosos y que convivan abuelos, padres e hijos. La brecha generacional es casi imperceptible, lo que permite que las relaciones familiares sean mucho más estrechas, y que se fomente el respeto y la veneración por los mayores, por lo que se garantiza la preservación de las tradiciones entre los más jóvenes. Las mujeres en Gambia tienen niveles educativos bajos; el índice de alfabetización femenino es del 37\%, frente a un 58.4\% masculino (Kaplan, 1998).

Lamin es una pequeña comunidad mandinka que se encuentra a 10 kilómetros del aeropuerto, con 25 mil habitantes aproximadamente, de los cuales el 40 por ciento son infantes (Kaplan, 1998). Esta comunidad sobrevive principalmente gracias a la agricultura y a la pesca, el resto de los oficios que destacan son la comercialización de productos varios, la confección de ropa y la construcción (Farjas, 2002).

\section{Abordaje teórico- metodológico}

No es fácil definir la identidad de un pueblo cuyas raíces de pertenencia, como se ha visto a lo largo del documento, fueron abruptamente modificadas. Actualmente es difícil que las comunidades, por más lejanas que se encuentren, no introduzcan nuevos conocimientos que atenten contra su autenticidad. Por lo tanto, es poco probable que una comunidad pueda mantenerse al margen de los 
avances tecnológicos, sobre todo en tiempos como los actuales donde la tecnología, los medios de comunicación y las redes sociales continuamente amenazan la identidad local e individual.

Se toma como punto de partida la definición de identidad social que propone Tajfel, quien explica que parte de la identidad del individuo se deriva del conocimiento de pertenencia a un grupo o grupos sociales conjuntamente con el significado valorativo y emocional asociado a esta pertenencia (Tajfel, 1981). Es decir, como lo señala Cirense (1987):

La identidad no se reduce a un haz de datos objetivos; resulta más bien de una selección operada subjetivamente. Es un reconocerse en (...) algo que tal vez solo en parte coincide con lo que efectivamente uno es. La identidad resulta de transformar un dato en valor. No es lo que uno realmente es, sino la imagen que cada quien se da de sí mismo. (p.13)

Bajo esta perspectiva se entiende que la sociedad es un conjunto de individuos que viven bajo unas mismas normas, leyes y cierto protocolo, y que tienen subculturas y subgrupos. Es así como en el interior de las sociedades del mundo se van construyendo conceptos más profundos que definen ciertos rasgos, como la identidad colectiva. En términos de Habermas (1983), las personas y los grupos se auto-identifican en y por su participación en acciones comunicativas, en la medida en que esa auto-identificación es reconocida intersubjetivamente. Por ello la identidad no es un atributo o una propiedad intrínseca del sujeto, sino que tiene un carácter intersubjetivo y relacional.

En el caso de las mujeres, Marcela Largarde explica cómo la identidad de las africanas se han ido construyendo: "las personas sometidas a formas particulares de explotación, opresión y marginación quienes, al recrear sus historias e identidades propias, realizan la crítica a la modernidad y a su más valiosa promesa: el desarrollo" (Lagarde, 1999, p.6). En ese mismo sentido Amina Mama (2001) reconoce que la idea de identidad para los africanos es interesante pues para la mayoría de ellos/ellas, sigue siendo tan desconcertante. "Parece que constantemente estamos buscando la integridad y unidad; para muchos africanos 
la identidad sigue siendo una búsqueda, algo todavía en proceso" (Mama, 2001, p.217).

El simple hecho de ser africanas y mujeres las coloca automáticamente en el segmento de estudio académico de la "otredad". Sin embargo, para profundizar en sus discursos, diálogos, voces, miradas y narraciones, tomamos en cuenta los estudios subalternos como aquellos que reconocen el estudio de las sociedades poscoloniales a partir de una narrativa histórica que considera a la "gente común", "las masas", "los olvidados" como auténticos catalizadores del devenir histórico. Todo ello por ser estos una alternativa para leer las historias de las sociedades "desde abajo" (Lagarde, 1999).

Para introducir el término de género en la cosmovisión de las africanas es importante reconocer primero que todas las culturas elaboran cosmovisiones sobre el género. En ese sentido, cada sociedad, cada pueblo, cada grupo y cada persona, tiene una particular concepción de género, basada en la propia cultura., De tal manera que es posible que cada persona a lo largo de su vida modifique su cosmovisión de género simplemente al vivir, porque cambia la persona, cambia la sociedad y con ella pueden transformarse valores, normas y maneras de juzgar los hechos (Lagarde, 1999).

Género es una categoría transdisciplinaria que desarrolla un enfoque globalizador y remite a los rasgos y funciones psicológicas y socioculturales que se le atribuyen a cada uno de los sexos en cada momento histórico y en cada sociedad. Las elaboraciones históricas de los géneros son sistemas de poder, con un discurso hegemónico y que pueden dar cuenta de la existencia de los conflictos sociales (Gamba, 2008).

Actualmente las mujeres se proponen conformar a su género como un sujeto social y político. De hecho lo están haciendo al nombrar entre ellas y frente a los otros sus semejanzas, al reconocerse e identificarse en sus diferencias, y al apoyarse y coaligarse para transformar sus opresivas condiciones colectivas de vida, pero también para compartir sus logros y los beneficios que se desprenden de su modernidad. 
Sin embargo, sería ingenuo y contradictorio contar las historias de las mujeres gambianas desde el punto de vista subalterno, intentando hablar por ellas. Por ello, esta investigación se sustenta desde la horizontalidad de la metodología Entre Voces, intentando describir la realidad de estas mujeres, pero desde su propia voz y sin opacar la voz del investigador, ya que la interacción durante cuatro años permitió formar un vínculo como madre, mujer, amiga, maestra y asesora.

Los retos de las mujeres en el mundo y las luchas por sus derechos se enfocan, a menudo, desde el punto de partida del cuestionamiento del sistema de género y de los arquetipos de feminidad que imponen los patrones culturales predominantes. (Nash, 2004, p. 27)

Como se mencionó anteriormente, es necesario profundizar en el contexto gambiano porque África entera es un continente lleno de matices que hay que considerar, y la situación de la mujer varía en cada una de las sociedades africanas. Es por eso que debemos ahondar en las especificaciones que se construyen en las narraciones visuales de estas mujeres, pues solo a través de dichos discursos se revelan circunstancias (económicas, políticas, sociales, legales, etc.) que contribuyen a facilitar la capacidad de actuación dentro de la sociedad que se estudia.

Las mujeres gambianas no huyen, no se excluyen y no se asumen como "subalternas". Desde sus diferentes concepciones, ellas aceptan y asimilan las diferencias que por tradición o imposición simplemente les tocó vivir, y son capaces de identificar sus diferencias con sus pares más cercanas: las europeas. Es común que para abordar el tema de mujeres africanas, se tengan en cuenta las discusiones de género o las feminidades para reconstruir la historia de esas comunidades, porque también allí se vive división sexual de trabajo donde la mujer es solo un soporte masculino y no el soporte económico, emocional, familiar y comunitario que actualmente tiene, por lo menos en el Gambia actual.

Frecuentemente la sociedad tiende a etiquetar las realidades africanas como un todo homogéneo por la poca intervención de las mujeres africanas, quienes por situaciones económicas principalmente, son minoría. Esto no significa 
que no haya historias que contar, por el contrario, hay muchas que no por pertenecer al subalterno carecen de validez. "Las mujeres como cualquier otro grupo subalterno, son agentes potenciales de cambio y transformación social, con la capacidad de impulsar y movilizar" (Mallon en Sandoval, 2010, p.174).

Para este estudio fue importante reconstruir la identidad de las mujeres gambianas a través de imágenes, por el significado que ellas otorgan a los elementos, poses y contextos que intervienen en la composición fotográfica. Además, al cruzarlas con sus discursos verbales proporcionaron una visión más clara y precisa de cómo se visualizan en el espacio público, ya que hay quien para entender la postura de estas mujeres es necesario adentrarse en las diversas interacciones que han sufrido a lo largo de la historia. Esto se refiere a interacciones de dominio y sumisión, e intersecciones y fusiones entre las tradiciones propias de las tribus africanas y las coloniales como movimientos feministas o de mujeres, según afirmó la sociologa Oyewùmí, durante la Primera Conferencia de Mujeres Africanas realizada en 2012.

Desde esta perspectiva y en el contexto africano, las concepciones de género resultan mucho más complejas. Por ejemplo, no se puede equiparar ser esposa con ser madre, dice Oyewùmí. Lo más significativo de todo esto es reconocer que el género no es una categoría necesariamente estática ni fija, ni definida como opuesta a otro género (el masculino), sino que se construye socioculturalmente y que, además, evoluciona en sus significados y contenidos con el tiempo; para cada mujer puede fácilmente modificarse durante su ciclo de vida o ser muy diferente para las mujeres de distintos contextos históricos, sociales y políticos (Oyewùmí, 2012).

Hasta aquí se han repasado algunos conceptos que vinculan identidad y género con empoderamiento, con sentirse reconocidos e integrados a un grupo. Sin pretender dar una definición exhaustiva del término, el empoderamiento de la mujer se refiere a un mayor control de la misma sobre su propia vida, su cuerpo y su entorno. Esto implica diversos aspectos tales como la libertad de movimiento y acción (autonomía), injerencia en los procesos de toma de decisiones (poder de 
decisión), acceso y control de recursos económicos, ausencia de violencia en contra de ella, acceso a la información e igualdad jurídica (Kishor, 2000, Oxaal y Baden, 1997).

El empoderamiento se refiere "al proceso por el cual aquellos a quienes se les ha negado la posibilidad de tomar decisiones de vida estratégicas adquieren tal capacidad" (Kabeer, 1999). Cuando hablamos de empoderamiento femenino, nos referimos "tanto al proceso, como al resultado del proceso a través del cual las mujeres ganan un mayor control sobre los recursos intelectuales y materiales, y desafían la ideología del patriarcado y la discriminación por género" (Batliwala, 1994). Este se relaciona con los cambios en la identidad, en la forma de percibirse a sí mismas y desde ese lugar, percibir a las (los) otros; es un proceso que implica dolor y sufrimiento porque se mueven estructuras, en el sentido de que lo que parecía incuestionable, ahora lo es, y no sólo eso, sino que las protagonistas encuentran la posibilidad de cambiarlo.

En el caso de las mujeres de Lamin, ellas ya conocían el 'sabor' del empoderamiento. Fueron ellas quienes fundaron la escuela Canarias Lamin Nursey School, un proyecto quizá un tanto rudimentario que en aquel entonces, alrededor del año 2000 según contaron, se creó a manera de guardería y por turnos se apoyaban unas a otras en el cuidado de los hijos para que así todas pudieran trabajar.

Paralelamente, esas mujeres hartas de no tener qué comer invadieron tierras que estaban aparentemente abandonadas y empezaron sembrarlas. No tardó mucho tiempo para que el dueño de las tierras las echara y destruyera sus sembradíos. Pero eso no impidió que ellas nuevamente se metieran y sembraran otra vez. Nuevamente las volvieron a echar y paulatinamente fue en aumento la violencia. Esto duró hasta que se movilizaron y el asunto llegó a oídos del presidente de Gambia, Yahya Jammeh, quien después de meses de negociaciones, giró instrucciones para que las tierras pasaran a ser de las mujeres de Lamin. Este ejemplo se ha extendido a otras comunidades de Gambia. 
Con el ejemplo anterior entendemos que el empoderamiento se da a nivel cognitivo en primera instancia. Es un proceso donde las mujeres hallan tiempos y espacios, y empiezan a reexaminar sus vidas en forma crítica y colectiva (Batliwala, 1994). Kabeer (1998) lo define como la expansión de la habilidad de las mujeres para hacer elecciones estratégicas de vida en un contexto donde previamente les estaba negado. Asimismo, el empoderamiento incluye tres niveles: el nivel personal, que implica desarrollar cambios en la forma en que la persona se autopercibe, se da mayor confianza individual y se generan diversas capacidades, incluyendo el liberarse de la opresión internalizada. El segundo nivel que tiene que ver con desarrollar habilidades para negociar e influenciar las relaciones de poder y la toma de decisiones en el interior de estas relaciones. En el tercer nivel se ubica el empoderamiento colectivo, que implica el trabajar en objetivos comunes, y con ello tener un impacto más amplio que trasciende el poder que cada individuo puede desarrollar (Martínez, 2000).

\section{El discurso fotográfico de las gambianas}

La herramienta principal de esta investigación, como se mencionó desde el principio, se basó en enfocar una rama de la educación artística como instrumento para promover la comprensión de la cultura visual. De entre una gama de opciones que les fueron presentadas a las mujeres, eligieron trabajar con cámaras, pues la idea era que ellas aprendieran a decodificar los valores y las ideas que encontramos en lo que llamamos cultura visual. Leer las imágenes como textos para revelar su política y sus propósitos ocultos es una forma de lectura. Otra forma es desarrollar la habilidad para usar las artes, comprendiendo sus valores y las condiciones de vida de los que viven en una sociedad multicultural (Marín, 2011).

La impartición de un taller fotográfico a través del cual se vertieron una serie de conocimientos teóricos y prácticos, además de una retroalimentación de la información como trasfondo de este proyecto, fueron los instrumentos a través de los cuales hilvanamos las palabras con las imágenes, lo que coadyuvó al 
esclarecimiento de las ideas. Basamos gran parte de este taller en la experiencia de Wendy Ewald (1969-1999), quien ha trabajado desde hace más de 30 años en talleres de este tipo en más de 20 sitios alrededor de todo el mundo ${ }^{6}$.

Además de esto, la experiencia de la doctora Corona Berkin (1988 a la fecha) en sus estudios en comunidades de la etnia Wixárika nos permiten apreciar cómo los procesos de apropiación de ideas contextualizadas y narraciones verbales y fotográficas otorgan a los estudiantes wixarikas de secundaria herramientas que facilitan el entendimiento de su realidad, donde los "otros" somos nosotros, no ellos. Sus imaginarios y realidades alternas les han permitido defender sus raíces no por el simple hecho de existir, sino porque a través de sus vivencias han entendido la diferencia.

Bajo este contexto se pensó en profundizar en ejes temáticos (que se detallan más adelante), ya que el taller se impartió durante un año, aunque las relaciones y proyectos con las mujeres se desarrollaron por espacio de cuatro años. Las clases se impartieron dos veces por semana, dos horas en la tarde y dos horas en sábado o domingo. En este estudio participaron 21 mujeres, de las cuales 18 eran nacidas y arraigadas en la comunidad Lamin, y 3 eran maestras de la escuela que decidieron participar voluntariamente. Las sesiones teóricas se realizaron en las instalaciones de la escuela, y para las sesiones prácticas se buscaron locaciones en donde ellas estuvieran de acuerdo. La introducción de los ejes temáticos fue un acompañamiento paulatino no solo en la maduración de los procesos propios de la fotografía, sino también como una manera de acompañarlas en la construcción de sus discursos narrativos. Por ello los resultados finales (que más adelante se describen) son reflejo de una maduración en su posicionamiento como mujeres, de tal forma que vinculan las palabras con

\footnotetext{
${ }^{6}$ Wendy Ewald ha propuesto y perfeccionando un método de creación artística participativa con la fotografía en diferentes comunidades alrededor del mundo, especialmente con niños y niñas, observó que al darles una cámara las fotos de los pequeños fotógrafos eran mucho más intimistas que las que ella tomaba, mostraban una visión menos objetiva y más personal desde sus propios valores culturales y sus vivencias.
} 
las imágenes, además del conjunto de elementos que introdujeron para crear su mensaje visual.

Los ejes fundamentales: Cómo quiero ser reconocida; Mis tradiciones y Mis sueños fueron temas producto de una deliberación grupal sobre lo que las mujeres deseaban comunicar al mundo, y lo que no deseaban perder en sus vidas. De ahí que la dinámica de trabajo, los títulos de cada eje y la recopilación de ideas fueron aportación de la autora, con el único objetivo de que la práctica fuera una reflexión interna que les replanteara una concepción acerca de lo que ellas esperan de sus vidas.

Bajo este contexto, es pertinente reiterar que la utilización de las cámaras fue el recurso que ellas escogieron, de entre una gama de herramientas como la pintura, la escultura y el collage que se les ofertó. Consideraron que la fotografía no requería demasiada capacitación y era la vía más rápida para poder expresar adecuadamente sus mensajes. El trabajo de campo se realizó por parejas, ya que en todas las composiciones las mujeres quisieron aparecer en las fotografías.

Cómo quiero ser reconocida: En este apartado las mujeres tenían que construir su propia imagen de cómo deseaban ser reconocidas o vistas en el espacio púbico, y decidir qué poner o qué dejar dentro de la imagen para complementar. Fue durante estas sesiones donde se introdujeron, de manera general, las reglas básicas de la fotografía, la regla de tercios, cómo, cuándo y qué enfocar, el posicionamiento de la luz, etc.

Mis tradiciones: Sobre este tema las mujeres debían hacer una reflexión sobre lo que significan sus tradiciones, y hacer una imagen que demostrará el arraigo a sus raíces, aquello que quieren que sus hijos y nietos sigan conservando, y de lo que se sienten orgullosas. En general debían proyectar la visión que les da su entorno, cuáles son esos espacios, lugares, experiencias, relaciones, nostalgias, acciones, etc., que reconocen en la construcción del espacio desde su casa, familia y comunidad. Además debían vincularlo con sus sentires, intentando imprimir en cada imagen los rasgos identitarios de su persona y su entorno. 
Mis sueños: En esta sesión las mujeres tenían mucho más conocimiento de los recursos fotográficos, por lo que tenían la libertad de apoyarse con varias imágenes en la redacción fotográfica con planos generales y a detalle. La práctica buscó que fueran capaces de externar desde su perspectiva el conocimiento de su entorno, sus propuestas, oficios, necesidades, injusticias, etc. Lo anterior para opinar, demandar, o dar a conocer al mundo cuáles son sus aspiraciones, cómo se proyectan en un futuro y hasta dónde son capaces de llegar. El ejercicio fue un rico recorrido de sentires, conocimientos y realidades ligados a propuestas de cambio.

\section{Resultados}

Llevar a cabo un taller fotográfico como una de las primeras actividades que se realizaron durante la creación de la Red de Mujeres Trabajadoras de Gambia, fue sin duda un gran acierto, pues esto permitió estrechar las relaciones entre ellas, hurgar y recordar sus orígenes y replantear planes a futuro. Las reflexiones en el taller pusieron al descubierto sentires, ambiciones, recuerdos, raíces y visiones del mundo. También repasaron sus relaciones, roles, saberes y deberes, lo que les permitió redefinirse y reconocerse tal cual son, con sus capacidades y debilidades.

Para Berger (2003), la visión actual sobre la mujer africana está cuestionando construcciones socioculturales estáticas y universales del género, sin perder de vista toda la complejidad y diversidad de roles que influyen, como la sexualidad, la maternidad, las formas femeninas de asociación y organización, las conexiones entre políticas nacionales, movimientos sociales y políticos de mujeres. Pareciera que, conforme pasa el tiempo, todos esos temas adquieren mayor importancia y es entonces que se intenta descubrir de dónde, cómo y por qué acceden o no las mujeres a determinados ámbitos de poder.

Lo anterior se hace presente en las composiciones fotográficas que hacen las mujeres. La práctica arrojó poco más de 600 fotografías, algunas de las cuales 
se clasificaron como temas libres y poco más de 400 fueron tomadas en cuenta en las categorizaciones que más abajo se explican. Todos los temas fueron abordados por parejas y las mujeres eran libres de buscar las locaciones que mejor se ajustaran a sus ideas, o bien llevarse las cámaras fotográficas a sus casas. En total se utilizaron seis cámaras digitales Nikon de ocho mega pixeles.

Acerca del primer tema Cómo quiero ser reconocida, se dispararon poco más de 145 fotografías, que retratan y reconocen su presencia en la cotidianidad. La mayoría de las mujeres decidió aparecer haciendo labores cotidianas como lavando ropa, preparando comida, barriendo, sembrando, o cargando en su cabeza una hielera con bebidas caseras y en la espalda su hijo atado con una rapa. Los discursos en general que las mujeres dieron acerca de las situaciones que fotografiaron expresaban que ellas deseaban ser reconocidas como mujeres trabajadoras, fuertes, madres de familia, emprendedoras y capaces de sacar adelante cualquier proyecto que tengan en mente.

Sin embargo, una de las fotos que más llamó la atención fue la de Hina Saho de 50 años. Ella es cocinera desde hace 5 años en la escuela Canarias Lamin Nursey School, y para esta sesión decidió posar sentada en la escuela, afuera de un salón, con una libreta en su regazo y un lápiz en su mano.

Al preguntarle por qué decidió posar así, respondió: "Yo quiero ser reconocida como una mujer, madre y abuela que estoy aprendiendo. La edad para mí no es una limitante" (H. Saho, comunicación personal, 13 de marzo de 2013).

Figura 2. Estoy Lavando

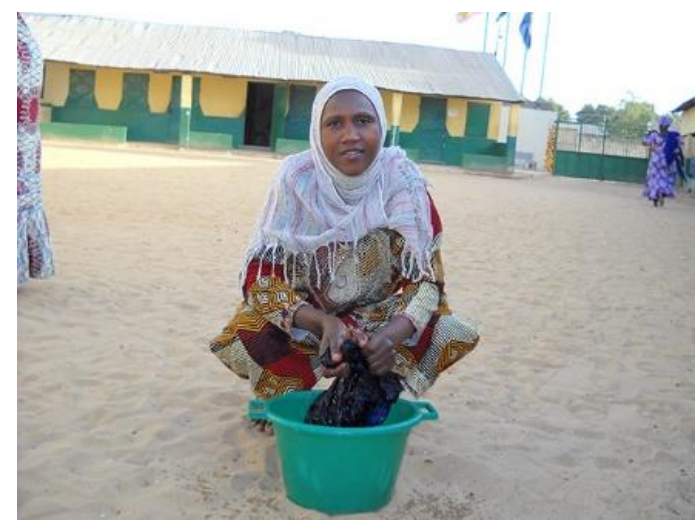


Autor: S. Saine (2013)

Figura 3. Vendiendo patatas

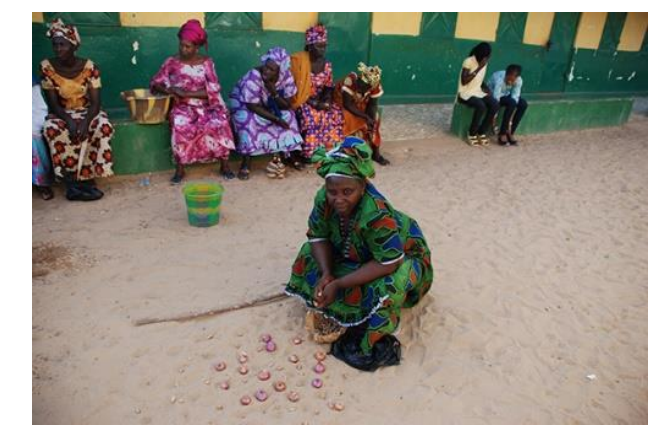

Autor: F. Manga (2013)

Figura 4. Soy abuela

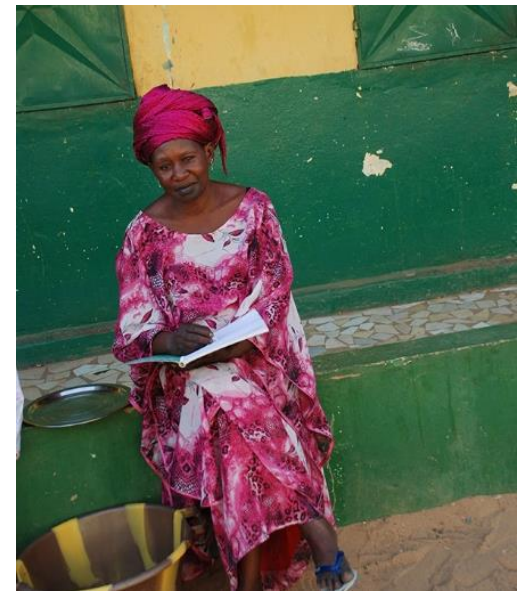

Autor: N. Buntu (2013)

El segundo tema Mis tradiciones, reunió alrededor de 115 fotografías. Las imágenes son un recorrido por las rutinas, juegos tradicionales, siembra de arroz, bailes, cosechas. En general son el reflejo de que la mujer africana está llena de energía. Son el motor silencioso que da vida a su comunidad. Sus actuares cotidianos son el mejor ejemplo de cómo transmiten sus tradiciones, enseñanzas y saberes a sus hijos.

A las fotografías les faltó narrar una parte que no se ve. Normalmente el taller se impartía a las cuatro de la tarde, pero después de algunas semanas pudimos ver que el tiempo no transcurre ni se rige a través del reloj como en 
occidente; ellas veían el cielo y calculaban el tiempo, o terminaban sus labores y entonces se presentaban al taller con más de una hora de retraso. La experiencia de vivir entre ellas, ver la fatiga y el cansancio en sus caras, permitió entender que a pesar de estar exhaustas y sudorosas de trabajar en la tierra, de lavar, o de cualquier cosa que ellas estuvieran haciendo, siempre estaban dispuestas a aprender con una sonrisa en su rostro, a contarnos cómo es su vida, cómo se aferran a sus tradiciones, porque finalmente esa es su esencia, y es así, con alegría, como aceptan sus roles y como se reinventan o se acoplan a las modernidades que les va dictando la vida.

Figura 5. Recogiendo Mangos

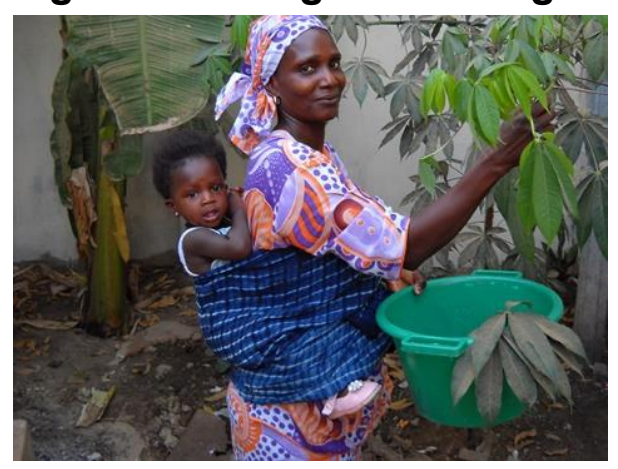

Autor: H. Saho (2013)

Figura 6. Soy Jola y Siembro Arroz

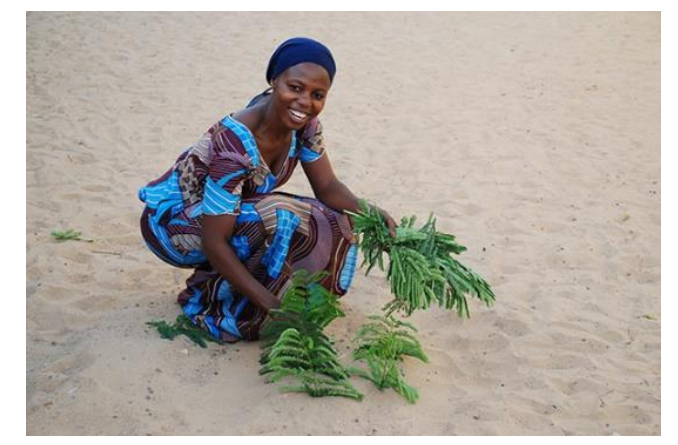

Autor: J. Bajatta (2013)

Finalmente en el tercer tema Mis sueños, las mujeres realizaron aproximadamente 155 fotografías. La narración visual expone no solo lo que son 
capaces de hacer, sino también retrata sus miedos más arraigados. Algunos retratos se apegan literalmente al significado de la palabra sueños.

En este apartado las señoras se retrataron soñando que una víbora las perseguía, que estaban a punto de quemarse, que el Kong kuran (personaje que espanta los malos espíritus en la ceremonia de la circuncisión) las alcanzaba, cortando mangos y comiéndoselos, o jugando con sus hijos. Se sueñan de mil maneras, pero sus proyecciones o sueños a futuro, en todos los casos, se refieren a los deseos de darles un presente mejor a sus hijos. Se sueñan con sus hijos terminando la escuela y obteniendo un buen trabajo fuera de Gambia, desde donde les mandan dinero para comprar un campao (casa) propio con muchas habitaciones.

\section{Figura 7. Esto es algo de lo que hacemos}

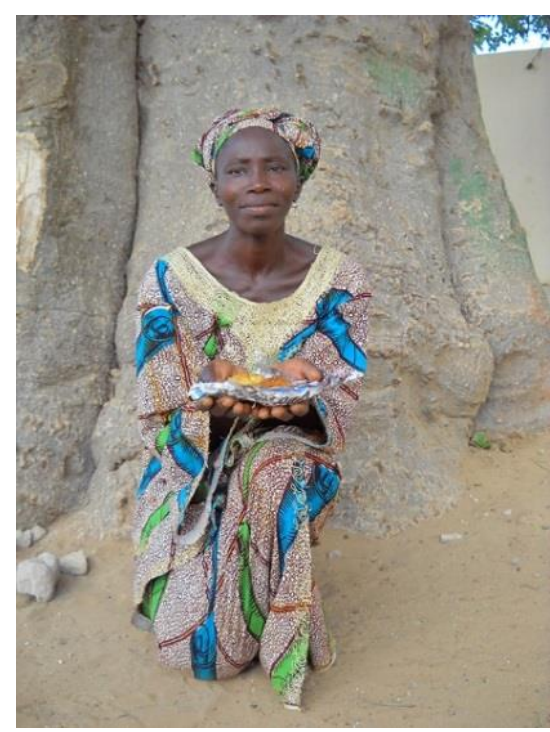

Autor: M. Jallow (2013) 
Figura 8. Me persigue la Víbora

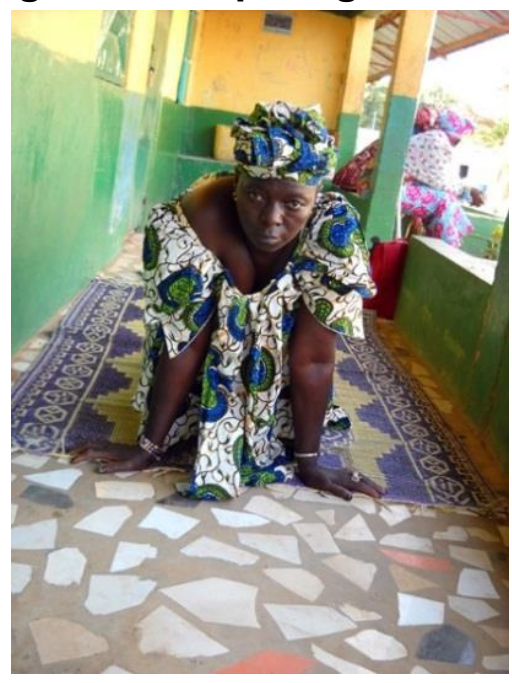

Autor: N. Kieteh (2013)

\section{Figura 9. Vuelo porque me quemo}

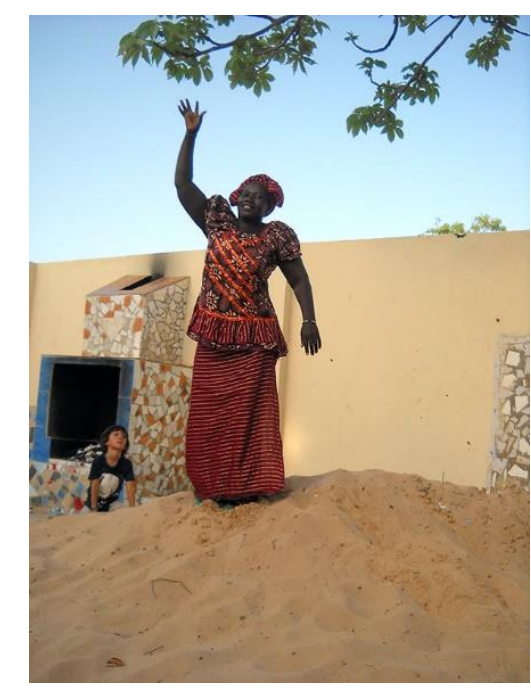

Autor: B. Touray (2013)

La narración fotográfica de las mujeres es muestra del lado sensible y fuerte de las gambianas. Este sentir se comparte en algunas partes del mundo, donde la pobreza, la falta de servicios de salud y las limitaciones de todo tipo, las llevan a adaptarse a las circunstancias y a ser creativas para hacer sus vidas más llevaderas, con el único objetivo de heredarles un futuro mejor a sus hijos. Son 
muestra de cómo afrontan con entusiasmo lo que les tocó vivir, sobre todo porque en este segmento de población sus problemas, dificultades o sobresaltos tienen que ver con la economía y la salud. Esta comunidad concretamente retrata su manera de sobrevivir y sobrellevar una vida digna en un contexto difícil.

Es importante resaltar que posterior a los meses con prácticas fotográficas, se llevaron a cabo dos sesiones de conclusiones para repasar lo aprendido, para revisar el material y encontrar entonces la simetría entre las imágenes, los discursos y sus necesidades. El taller les recordó la importancia de mantenerse unidas, de abrazar sus raíces, de no perder la brújula entre sus saberes y sus necesidades. A partir de este trabajo las mujeres fueron capaces de rescatar sus conocimientos ancestrales y transformarlos en productos que a través de una cooperativa puedan comercializar, con el objetivo de que sean ellas quienes propongan proyectos en beneficio de su comunidad, puesto que nadie mejor que ellas sabe de sus necesidades. El ejercicio también permitió recordar que si bien se asumen diferentes, esa diferencia les da el poder de decidir cómo y hasta dónde quieren llegar. Quedó claro que no aspiran a tener una vida como las mujeres europeas, como lo explicó Francess Manga, maestra de arte de preescolar: "Me gusta ser africana, me gusta la tranquilidad con la que vivo, lo único que me gustaría cambiar es tener la certeza de que siempre tendré que comer y donde vivir" (F. Manga, comunicación personal, 8 de octubre de 2014).

\section{Conclusiones}

Cuando a las mujeres se les ha negado la oportunidad de decidir, con mucha frecuencia encontramos casos de vida que carecen del sentido de planear, definir metas y actuar efectivamente para lograrlas. Pero estas metas también pueden ser fuertemente influenciadas por los valores de la sociedad en la cual viven, por lo que en ocasiones pueden replicar, en lugar de desafiar, las estructuras de injusticia. El peso de la socialización lo expresa elocuentemente una mujer activista de Prishtina, Kosovo: "Hay una educación en la familia africana: primero, no debes hablar porque eres una mujer, luego más adelante no 
debes hablar porque nadie se va a casar contigo, más tarde no debes hablar porque eres una recién casada. Finalmente, tal vez tengas la oportunidad de hablar, pero no lo haces porque te has olvidado de cómo hacerlo"7.

Intentar desdibujar un panorama africano es por demás difícil y contradictorio, ya que corremos el riesgo de no entender las necesidades más simples del pueblo africano, y es porque no comprendemos el contexto cultural al que pertenece. Desde la experiencia de este estudio, en el primer año a simple vista se encontraron muchas contradicciones en la sociedad gambiana, que no se aclararon hasta que terminó el estudio (cuatro años después). No quedaba claro cómo es que las mujeres son capaces de emprender cualquier cosa que se propongan, y no fueran capaces de promover que llegue agua, luz o gas a su campao para hacer su vida más simple y cómoda. Estamos convencidos que son reflexiones en las que se antepone la experiencia social occidental, y es evidente que ellas no necesitan "facilitarse" la vida. Para ellas cocinar toda la mañana, sentarse junto a la fogata, charlar y descansar un poco mientras cocinan, es parte de ser mujer. Ir las fuentes de agua y llenar uno o dos bidones de agua mientras charlan con alguna vecina, es señal de vitalidad y salud. Queda claro que sus prioridades son otras, y muy diferentes a las nuestras.

No obstante y a pesar de estas situaciones y apreciaciones, en Gambia las mujeres están promocionando cambios positivos por medio de asociaciones de mujeres; las mejoras vendrán a través de su participación en espacios de toma de decisiones y de poder. Mientras tanto, para ellas es más importante de momento fundar talleres de costura, jabón, artesanías, o productos que puedan comercializar rápidamente con apoyo de alguna ONG o entre el turismo solidario que últimamente invade a Gambia.

\footnotetext{
7 Una activista en el Grupo de Mujeres Drita, Prishtina, Kosovo, según se referenció en las Federaciones Internacionales de Helsinki para los Derechos Humanos: International Helsinki Federations for Human Rights (IHF), Women 2000: An Investigation into the Status of Women's Rights in Central and South-eastern Europe and the Newly Independent States (Helsinki: IHF, 2000).
} 
Nuestra responsabilidad, y coincido con Elena Poniatowska (2001) cuando se refiere al trabajo que muchas mujeres, investigadoras, académicas, o voluntarias hacen en las comunidades, es entender que una cosa es alinearse con los pobres y los indígenas desposeídos y otra ahondar en su propia visión del mundo, entender su construcción del yo y los otros, su manera de percibir el cuerpo y la reproducción. Se llega a un tipo muy diferente de comprensión cuando somos capaces de respetar y entender sus referencias simbólicas en conexión con su vida cotidiana y religiosa. Se trata de dos momentos del compromiso y de dos niveles de la comprensión. Se puede tener lo uno sin lo otro.

Muchas veces las mujeres que trabajan con mujeres indígenas pueden ser colocadas en alguno de los lugares dentro de un continuum que presta atención sólo a las injusticias materiales y a la opresión de clase. Por otra parte, hay que esforzarse por entender el universo simbólico, religioso y cosmológico en el que esas mujeres tienen un lugar. De lo contrario se corre el riesgo de actuar como "neocolonialistas" o resultar unas intrusas. Si se empieza por forzar un cambio sin respetar sus propios procesos, acaba haciéndose necesario cambiarlas para adaptarlas a las propias concepciones de lo que es la libertad, la justicia y los derechos (Poniatowska, 2001).

El cruzamiento informativo entre lo que relataron y retrataron hace evidente que, como muchas personas, no sabemos qué depare el futuro. No alcanzamos a entender y menos a verbalizar los cambios que acontecen a nuestro alrededor. Sin embargo, estamos conscientes que existen otras realidades quizá mejores o peores, dependiendo desde donde se enfoque. Para las africanas construir su realidad inmediata es alimentar su imaginación a través de ecos que llegan por conversaciones o experiencias de alguien que vive en otra parte del mundo, que imaginan cuando ven un recorte de periódico, una película o una telenovela.

El caso de las mujeres gambianas no es diferente, ellas son conscientes de las transformaciones que ha sufrido su país, como reconoce Sammeh Jatta, mujer de 70 años, madre de cinco hijos y quien todavía a esa edad va al río a recoger ostras. 
Nunca fui a la escuela; sin embargo, yo sabía que mi hija tenía que estudiar con los tubaps (hombre o mujer blanca), porque sólo así podía ofrecerle un mundo diferente al mío, en donde la guerra, las constantes ausencias y las interminables crisis económicas son pan de todos los días. Yo he visto como algunos tubaps mataron a mi pueblo, pero también sé que sin los tubaps no estuvieran aquí y seríamos más pobres. (S. Jatta, comunicación personal, 23 de mayo de 2013)

Las palabras de Sammeh pueden ser contradictorias, pero permiten comprender mejor la teoría. Se percibe con claridad cómo a través de sus vivencias y de cada momento histórico político, social y cultural por el que ha atravesado su país, se ha reinventado a sí misma. Es justamente aquí en donde se vislumbran los estragos de un mundo global y de un diálogo monologado. Quizá alguien pudiera batirse en un sinfín de teorías y analizar las historias desde diferentes posturas y corrientes. Sin embargo, son las "sin voz" quienes descubrieron que efectivamente tienen historias que contar.

No se puede entender ningún movimiento sin la recuperación de esas historias; la decolonización empieza con este rescate. La ayuda internacional debe insertarse en países como Gambia, a partir de su cosmovisión de vida y respetando la forma en que se apropian de los ecos de la poscolonialidad para construir en su diferencia. A fin de cuentas, son los africanos los poseedores de un juego de historias únicas, pero quizá este anhelo es solo una utopía.

A manera de conclusión puede decirse que los estudios que promuevan los diálogos visuales pueden ser de mucha ayuda para identificar con mayor claridad lo que pasa con el empoderamiento, las tradiciones, la reconstrucción del contexto que se estudie y un sinfín de historias solo visibles a través de imágenes hechas por los actores sociales. Es la reactualización de investigaciones audiovisuales lo que permite enfocar culturas que poco a poco, a su paso y a su tiempo, se reconstruyen a través de la palabra, el testimonio y las creaciones artísticas en medio de un correr vertiginoso de la modernidad tecnológica. 


\section{Referencias Bibliográficas}

Algora, M. D. (2003). La Historia Contemporánea en África y sus efectos sobre la mujer en la sociedad subsahariana. Cuadernos de Historia Contemporánea, (extraordinario), 179-190.

Batliwala, S. (1994). The meaning of women's empowerment: New concepts from action. In Gita Sen. En Germain A. y Lincoln C. (Eds.), Population Policies reconsidered: health, empowerment and rights (pp.135-201). Boston: MD Harvard University Press.

Cirese, Alberto. (1987). 11 Molise e la sua identita. Basilicata, n 516, mayo-junio de 1987, pp. 13.

Corona, S. (2007). Entre voces... Fragmentos de educación "entrecultural". México: Universidad de Guadalajara.

Deere, D.C. y León, M. (2002) Género, propiedad y empoderamiento: tierra, estado y mercado en América Latina. México: Universidad Nacional Autónoma de México y Flacso. Recuperado de http://www.bdigital.unal.edu.co/1388/8/04CAPI03.pdf

Ewald, W. (1999). Secret Games: Collaborative Works with Children 19691999.EUA: Universidad de Pennsylvania.

Fanon, F. (1972). L'an $V$ de la Révolution algérienne [1959] [Reeditado bajo el título Sociologie d'une revolution. París: F.M. Petite collection Maspéro.

Fernández, Olaya. 2011. Las mujeres en el Islam: una aproximación. Revista Brocar (35), pp. 267-286. Recuperado de

https://publicaciones.unirioja.es/ojs/index.php/brocar/article/view/1606/1503

Gamba, S. (2008). ¿Qué es la perspectiva de Género y los estudios de Género? España: Ed. Biblos

Habermas, J. (1983). La reconstrucción del materialismo histórico. Madrid: Editorial Taurus

Jabardo, M. (2005). Migraciones y género. Cuando el continente africano se hace pequeño. Revista española de Desarrollo y cooperación, (16), 81-97. Recuperado de http://xenero.webs.uvigo.es/profesorado/iria vazquez/continente.pdf

Kabeer, N. (1998). Realidades trastocadas. Las jerarquías de género en el desarrollo del pensamiento. México: Paidós.

Kane, K. (2007). Gambia y Senegal. España: Geo Planeta.

Kapplan, C. (1998). De Senegambia a Cataluña. Proceso de aculturación e integración. Barcelona: Ed. La Caixa.

Kishor, S. (2000). Empowerment of women in Egypt and links to the survival and health of their infants." In Women's Empowerment and Demographic Processes: Moving Beyond Cairo. Harriet Presser and Gita Sen. New York: Ed. Oxford University Press. 
Lagarde, M. (1996). Feminismo, Género y Desarrollo Humano. Madrid: Horas y horas.

Lütz, H. (1991). Migrant Women of "Islamic Background". Images and Selflmages. Middle East Research Associates. Occasional Paper n. 11.

Mama, A. (2001). Challenging Subjects: Gender and Power in Africa Contexts. African Sociological Review 5 (2), 63-73.

Marín, R. (2011). La investigación en Educación Artística. Educatio Siglo XXI, 29 (1), 11-230.

Martínez, B. (2000). Género, empoderamiento y sustentabilidad: una experiencia artesanal de mujeres indígenas. México: Serie PEMSA2 GIMTRAP.

Mallon, F. (2010) Promesas y dilemas de los estudios subalternos. En P. Sandoval (comp.), Repensando la subalternidad. Miradas críticas desde/sobre América Latina. (pp. 151-196) Lima: Instituto de Estudios Peruanos.

Moualhi, D. (1997). Las migradas magrebíes en Cataluña (Área Metropolitana de Barcelona): El contexto de origen y las motivaciones de emigración. Tesina de Mágister, Universidad Autónoma de Barcelona.

Nash, M. (2004). Repensar las representaciones mediáticas de las mujeres migrantes. Quaderns de la Mediterränia. (Ejemplar dedicado a: Women in the Mediterranean Mirror) Universidad de Barcelona (7) (pp. 59-62).

Obioma, N. (2005). Escenarios para la Lucha Feminista Transnacional. En la Primera Conferencia Internacional Sobre las Mujeres de África y de la Diáspora Africana. Sudáfrica.

Oyewùmí, Oyèrónké (2012). Visualizing the Body. Western Theories and African Subjects. En Oyèrónké Oyewùmí (Coord.), African Gender Studies. A Reader (pp. 137-151). New York: Palgrave.

Oxaal, Z. \& Baden, S. (1997). Gender and empowerment: definitions, approaches and implications for policy. Bridge Report No. 40. Sussex: Institute of Development Studies.

Poniatowska, E. (2001, 13 de marzo). Perfil de La Jornada. Diario La Jornada, p.3 Tajfel, H. (1981). Human groups and social categories. Cambridge University Press. Versión en castellano, Barcelona: Herder.

Wang, C. y Burris, M. (1997). Photovoice: Concept, Methodology, and Use for Participatory Needs Assessment. Health Education \& Behavoir, Vol. 24 (3): 369387.

\section{Para citar este artículo:}

Landeros, I. (2016). Identidad y empoderamiento de las mujeres gambianas a través de discursos fotográficos. Collectivus, Revista de Ciencias Sociales, 3(1), 935. doi: http://dx.doi.org/10.15648/Coll.1.2016.2 